\title{
IMPLEMENTATION AND SYSTEMATIZATION OF A COMPREHENSIVE MEDICATION MANAGEMENT (CMM) SERVICE DELIVERED TO WOMEN WITH BREAST CANCER
}

\author{
MARIA ÂNGELA RIBEIRO ${ }^{1,3 *}$, SIMONE DE ARAÚJO MEDINA MENDONÇA², AGNES FONSECA RIBEIRO FILARDI ${ }^{1}$, \\ ANNA CLAÚDIA YOKOYAMA DOS ANJOS ${ }^{3}$, DJENANE RAMALHO-DE-OLIVEIRA ${ }^{1}$
}

${ }^{1}$ Departament of Social Pharmacy, Center for Pharmaceutical Care Studies/Federal University of Minas Gerais (UFMG), Belo Horizonte,

MG, Brazil. ${ }^{2}$ Departament of life Sciencies , Federal University of Juiz de Fora (UFJF)_Campus Governador Valadares, MG, Brazil. ${ }^{3}$ Departament of Healty Sciencies , Federal University of Uberlândia (UFU), Uberlândia, MG, Brazil. Email: ribeiromaribeiro31@gmail.com

Received: 22 July 2017, Revised and Accepted: 11 October 2017

ABSTRACT

Objective: The aim of the present study was to describe the process of implementation and systematization of a comprehensive medication management (CMM) service, from the perspective of the participants involved, in a high complexity service that cares for women with breast cancer in Brazil.

Methods: A qualitative study that utilized action research that followed the procedures proposed by Kurt Lewin and the ethical and clinical principles of pharmaceutical care practice. Data collection techniques were participant observation between August 2014 and December 2016, semi-structured interviews with eight pharmacists and pharmacy residents, field notes, and analysis of documents.

Results: Six major themes emerged in four cycles of the action research process: (1) Resistance is human; the management of conflict is necessary; (2) insecurity with being a clinician; (3) management of change supported by driving forces; (4) pharmaceutical care fostering professionals' selfefficacy; (5) documentation as the conducting wire of the practice; and (6) the advantages of a systematized practice.

Conclusion: The study offered an understanding of the process of implementation of CMM services from the perspective of pharmacists. It produced knowledge on the experiences of pharmacists as they lived through the process of transformation of their professional practice to offer a patientcentered and systematized service. The framework of Lewin supported the introduction of a new work path for pharmacists, which could be operationalized as an innovative technology for the Brazilian health-care system: CMM services.

Keywords: Comprehensive medication management services, Medication therapy management, Pharmaceutical care, Breast cancer, Action research, Qualitative research.

(c) 2018 The Authors. Published by Innovare Academic Sciences Pvt Ltd. This is an open access article under the CC BY license (http://creativecommons. org/licenses/by/4. 0/) DOI: http://dx.doi.org/10.22159/ajpcr.2018.v11i1.21537

\section{INTRODUCTION}

According to the protocol of the Brazilian Network of Health Care for People with Chronic Illnesses cancer is an important public health problem recognized as a chronic condition that requires comprehensive care [1]. Chronic health conditions demand constant monitoring of clinical parameters by health-care professionals and by patients as well as greater care coordination by diverse practitioners and between different levels of care [2-4]. The monitoring of these conditions has to be continuous due to their long-term course and the possibility of complications in the long run [2]. Between the different types of cancer, breast cancer is the most common in women worldwide. In Brazil, according to the National Institute of Cancer (INCA), 57.960 new cases will be diagnosed between the years 2016 and 2017 [5]. On the other hand, the survival rate in 5 years is growing due to early diagnosis and to the consolidation of effective treatments. Hormone therapy has been essential due to its several therapeutic options, good safety profile, and high effectiveness [6]. Along with the treatments for breast cancer, many patients use other medications for their associated comorbidities such as hypertension, diabetes, hyperlipidemia, hypothyroidism, osteoporosis, and obesity, conditions whose incidence tend to increase with age [1]. In this context, the control of patients' glycemia, cholesterol, blood pressure, between other parameters, depend on social, cultural, emotional, economic, and therapeutic factors that can be better understood and managed by several professionals. Furthermore, the prevalence of multiple chronic health conditions leads to a common situation between patients with cancer, polypharmacy $[7,8]$, which is the use of several medications for different conditions including some induced by the oncological treatment itself. Polypharmacy is also a result of several prescriptions by multiple professionals for the same patient without an appropriate communication between them. Even though drug therapy is one of the most cost-effective interventions in health care, its use has been associated with negative results known as drug therapy problems (DTP), which can produce not only a negative economic impact but also human suffering [2,9]. DTP is an undesirable event experienced by a patient that involves, or is suspected to involve drug therapy and that prevents the achievement of goals of therapy $[2,10,11]$. These problems have been widely discussed in the scientific literature because it has been shown to increase the morbidity and mortality related to drug therapy $[2,11,12]$. Pharmaceutical care is a professional practice developed in the United States of America in the past century with the goal to prevent and resolve DTP $[2,10,11]$. It involves face-to-face encounters between a practitioner and a patient where the first takes responsibility to meet the patient's medicationrelated needs. The pharmaceutical care practitioner accepts a specific philosophy of practice, follows standards of practice that involves the use of a systematic thought process to make decisions about drug therapy, and have a practice management system that supports the development of a high-quality and sustainable clinical service [12]. In Brazil, pharmaceutical care practice is legally supported since $12 / 30 / 2010$ with the publication of Decree 4283 and then the publication of the resolution number $585 / 2013$ by the Federal Board of Pharmacy (Conselho Federal de Farmácia), that regulates the clinical attributions of pharmacists $[13,14]$. The last one permits the pharmacist 
to use his or her knowledge of pharmacotherapy to provide patient care in a comprehensive and systematic manner. Pharmaceutical care, that is operationalized through the delivery of comprehensive medication management (CMM) services, has been shown to produce clinical, economic and humanistic results, which justify its consolidation and expansion in the health-care systems around the world [2,10-12,15]. In many countries, such as the USA, United Kingdom, Australia, Canada, and Singapore, these services have been successfully implemented. However, it is still a service in an embryonic stage in Brazil. In the oncology area, to the best of our knowledge, it cannot be found literature that depicts the experiences of pharmacists with the implementation of CMM services. The studied scenario, an oncology clinic for women with breast cancer, had been delivering pharmacy clinical services for several years. However, these services were mostly focused on analyzing prescriptions, identifying adverse drug reactions and drug interactions, and guaranteeing patients' compliance with prescribed medications. In other words, it was understood that the services were not focused on patients nor followed the philosophical and methodological premises of pharmaceutical care practice, which were the interest of the research group $[2,10,11]$. Thus, the objective of the present study was to describe the process of implementation and systematization of a CMM service, from the perspective of the participants involved, in a high complexity institution that cares for women with breast cancer in Brazil.

\section{METHODS}

\section{Study design}

This was a qualitative study that utilized action research that followed the procedures proposed by Kurt Lewin [16-19] and the ethical and clinical principles of pharmaceutical care practice [2,11]. Action research can be understood as a reflective process that demands the participation of the researcher and the participants in the studied social action, in which all participants converge into researchers [16,17]. It also allows for a broad and overt interaction between researcher and the individuals involved in the investigated situation resulting in the definition of priorities and solutions to be worked out $[16,17]$. The Lewin three stage of change method was utilized, in which action, research and education form a triangle that should be seen as a unity. Action research is described by Lewin as a spiral of stages in cycles of planning, action, observation, critical reflection, and discoveries that are followed by re-planning and retro feedback for each cycle of the research. The spirals confer rigor to the study since all data and actions go through a process of critical revision that permits one to review any bias and inconsistencies of previous cycles. These spirals are considered a fundamental procedure to organize the cognitive processes that take place during an action research project $[18,19]$. Group dynamics and field theory were also utilized as they identify the forces that operate inside the groups, their origins, consequences and conditions that can modify the behaviors of a group $[17,19]$. These forces are restrictive or encouraging, and consequently, they assist in an action research project as we monitor the forces that interfere with the changes in participants' behaviors. The use of these tools can foster authenticity in the group relations allowing the individuals to be more creative inside the group and democratizing the relations inter- and intra-groups without manipulation [19]. Pharmaceutical care practice, as developed by Cipolle et al. [11] was utilized as the framework to interpret the data associated with the process of implementation of CMM services and participants' responses to this process.

\section{Setting}

Data were collected in a large public hospital of high complexity in the State of Minas Gerais, Brazil. This hospital is a reference for over 3 million people from 86 municipalities [20]. It is also an important reference for the treatment of women with breast cancer in the region.

\section{Sample and recruitment}

Participants of the study were intentionally selected with a total of 14 pharmacists and seven pharmacy residents in oncology (Table 1).
Table 1: Characteristics of the pharmacists in the practice scenario studied

\begin{tabular}{ll}
\hline Characteristics (n=21) & Occurrence (100\%) \\
\hline Age (years) & $06(28.54)$ \\
$\leq 30$ & $04(19.07)$ \\
$31-40$ & $07(33.33)$ \\
$41-50$ & $04(19.06)$ \\
$\geq 50$ & $06(28.54)$ \\
Education & $07(33.33)$ \\
Bachelor of pharmacy & \\
Residents in training & $08(38.13)$ \\
& \\
Master's degree & $08(38.13)$ \\
Type of practice & $12(57.14)$ \\
Hospital - inpatients & $01(04.73)$ \\
Hospital - outpatient care & \\
LTC & $05(23.86)$ \\
Length of practice (years) & $12(57.08)$ \\
s10 & $04(19.06)$ \\
11-30 &
\end{tabular}

LTC: Long-term care

From the total, four pharmacists, including the first author, and five residents delivered direct care to women with breast cancer. During the research process, the first author was positioned as the main researcher and as a participant at the same time that the other participants also became researchers.

\section{Data collection}

Participant observation was carried out for 28 months to understand the processes related to the implementation of CMM services. During this time, pharmacists and residents were being invited to reflect on their practices with patients as well as trained according to the principles of pharmaceutical care practice. Participant observation allowed an in-depth understanding of the discourses, feelings and actions of participants in the context where they occurred and the reason why they happened $[16,17]$. All impressions and the researcher's reflections were registered in a field journal during the entire period of fieldwork. Semi-structured interviews were carried out with 8 pharmacists, being 5 residents, from August of 2014 to December of 2016. The interviews were conducted in the hospital and lasted $40 \mathrm{~min}$ on average. The interviews were conducted in different moments during the research process to capture pharmacists' perceptions and the changes they lived through over time. All interviews were audiotaped and transcribed verbatim by the first author. Practice documents such as projects and the documentation system were analyzed and adapted to meet the requirements of the practice standards of pharmaceutical care.

\section{Data analysis}

Thematic analysis was performed according to the following process [21,22]: (a) All field notes and interviews were read multiple times to familiarize with the data; (b) initial coding was carried out with the identification of the meanings attributed to the following: Learnings about pharmaceutical care practice, implementation of CMM services, experiences with the process of transformation to a patientcentered pharmacist that follows the standards of practice proposed by pharmaceutical care; (c) definition of analytical categories as a result of structuring elements of participants' discourses; (d) considering the dynamic nature of qualitative data analysis, the initial themes were reexamined and renamed according to new discoveries throughout data collection; (e) after the initial analysis, a collaborative analysis was made involving all coauthors. Each researcher analyzed the data separately, and meetings were held to check agreement or lack off between the authors; and (f) interpretation of the discourses and definition of themes that dialog with the research objectives and the theoretical framework of the study. The Software Nvivo 10 was utilized to organize and analyze the data. 
Ethical approval

This research followed the ethical principles of Helsinki Declaration. The project was approved by the Ethics Committee of the Universidade Federal de Minas Gerais (CAAE -25780314.4.3004.5152) in May of 2014. All participants signed the consent form after being informed about all the details of the research. All participants' names used in the text are fictitious to guarantee their anonymity.

\section{RESULTS}

Six different themes were identified during data analysis and interpretation. These themes emerged within the spirals (Fig. 1). The spirals that occurred in the action research project and are represented in four cycles (Table 2). The cycles represent participants' experiences and activities that took place since their initial engagement with the project, their invitation to reflect on the possibility of change from a medication-centered professional to a patient-centered practitioner, their participation in the provided training and the implementation of CMM services. During the entire research process, it was necessary to train pharmacists on the main components of pharmaceutical care practice. This happened in three cycles of theory-practice training followed by the application of knowledge during the provision of direct patient care by participants. Following the framework and procedures proposed by action research, the training occurred during group sessions following the movement of spirals that comprised planning, action, observation, critical reflection, and new discoveries according

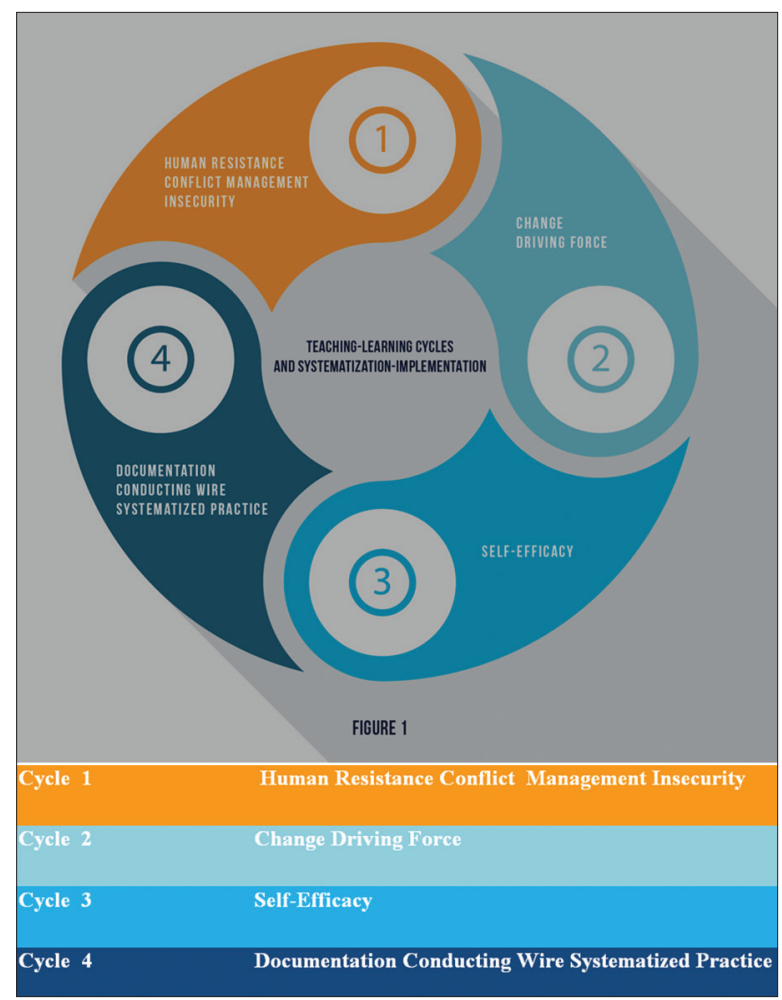

Fig. 1: The self-reflexive teaching-learning cycles and systematization and implementation of comprehensive medication management services with the aid of action research by Kurt Lewin to the needs of the participants. The training of pharmacists was the central portion of the research and provided all the theoretical and methodological groundwork for the implementation and systematization of CMM services

The training of pharmacists in the philosophy, patient care process and practice management system associated with pharmaceutical care practice provided the minimum necessary standards for pharmacists to build a single service and be able to communicate effectively between themselves and with other professionals. The discussions about practice management fostered the planning and implementation of an organized service. The results are composed of themes and sub-themes that emerged in four cycles that happened chronologically, as described underneath

\section{Cycle 1}

During the first encounter between researcher and participants in $08 / 12 / 2014$, when the training started, the previous knowledge of the participants was investigated. Afterward, an initial training plan was presented, and the participants were invited to respond, discuss and change it as they saw fit. The plan had the goal to impart knowledge about pharmaceutical care, to train clinical skills and to stimulate reflection about the possibility of changing the reality of participants. A large change would be necessary if these clinical pharmacists were to become pharmaceutical care practitioners. The training material utilized in this research was similar, with some adaptations, to the pharmaceutical care class, taught to pharmacy students and professional pharmacists by the Center for Pharmaceutical Care Studies of the Universidade Federal de Minas Gerais (Centro de Estudos em Atenção Farmacêutica - UFMG) [23]. The first period extended until 02/15/2015 or 6 months. During this time, participants were observed as they dealt with the theory and the practice of direct patient care and the full training was implemented. However, from the 19 pharmacists that started the process, only 10 completed it. Two of them gave up at the first group meeting, and the others left over time. As recognized by action researchers, the groups lived through a movement of fight and flee [24]. At first, "flee" was manifested when some participants decided not to participate in the proposed activities, or not to express their opinions as they diverge from the other members of the group, or when they did not pursue the reading of texts or other activities proposed during the training. And finally, the experience of "flee" was represented by withdrawal from the group. By the end of Cycle 1, it was observed several conflicts and resistance to apply the new learnings in practice, which led some participants to choose not to work directly with patients. For participants, the main reason to withdraw was their multiple management and logistic roles in the hospital as well as the demand of the board of pharmacy that requires pharmacists to compound cytostatic medications. According to them, all these activities left no time for them to care for patients and compromised their follow-up consultations. This cycle was interrupted before the anticipated time. An emergency meeting took place, and a new research team was defined, which included some pharmacists and the pharmacy residents. Two main themes arose during this cycle, as described below.

\section{Resistance is human, the management of conflict is necessary}

The manifestations of resistance were strong between participants at the beginning of the research process. During one clinical activity that was part of the training, one pharmacist mentioned "when things are pretty busy at the pharmacy, we are here only acting as clinicians!'

Table 2: Themes and sub-themes that emerged during the study $(n=21)$

\begin{tabular}{llll}
\hline Cycle $\mathbf{1}$ & Cycle 2 & Cycle 3 & Cycle 4 \\
\hline 1. Resistance is human, the & 3. Management of change supported by & 4. Pharmaceutical care & 5. Documentation as the \\
management of conflict is & driving forces & fostering professionals' & conducting wire of the practice \\
necessary & 3.1. Pharmaceutical care in practice & self-efficacy & 6. The advantages of a \\
2. Insecurity with being a clinician & 3.2. Pharmaceutical care is not done alone & & systematized practice \\
\hline
\end{tabular}


This account was unexpected and seemed worrisome to most people present at the moment. A few days later another pharmacist came to one of the researchers saying: "I understand that you invested in me, but I apologize... I prefer not to take care of patients here at the oncology clinic. I am not following the process. I am not studying as I am supposed to ... and for sure other people will be able to contribute more than me."

The withdrawal was respected, but the researchers still tried to sensitize the participants about the importance of the service for patients. However, they were not successful. Since the logistic and managerial activities usually took a lot of time from the pharmacists, it was suggested that some pharmacists might assume more of a managerial role while others could function mostly as clinicians. The group manifested a strong resistance to that idea, as illustrated here: "To be exclusive is not important. I see no problem in distributing our activities! We can share responsibilities, sometimes we can do compounding, other times dispensing and also patient care."

These experiences represented important barriers to the initial implementation of the CMM service because a novice clinician needs to focus on taking care of patients to be able to learn, to reflect on their experiences and to take care of as many patients as possible to gain expertise. Moreover, these activities are very different and demand diverse dispositions, approaches and responsibilities from the same person. Thus, they should preferably be executed by different individuals, or they should at least be executed in different days so that the pharmacist can anticipate and plan for them.

\section{Insecurity with being a clinician}

As pharmacists became more knowledgeable about the practice, understood and accepted the philosophy of practice and started applying the rational decision-making process with patients, they realized that patient care is not an easy task. First, pharmacists felt ambivalent about their role in the logistics of the pharmacy and their responsibility toward the patient and other members of the healthcare team. They felt uncertain about their professional identity as they were interested to pursue innovative activities as clinicians, and, at the same time, they were insecure about executing these same activities. Therefore, the path seemed nebulous as commented by this participant: "Some are very insecure with the clinical role. I see that they want to assume this responsibility because many feel that they should be better utilized as health-care professionals. They think that their knowledge should be put in favor of the patient. However, they are fearful of patient care. Hence, they do not fight for it."

\section{Cycle 2}

The second period of training went from $05 / 18 / 2015$ to $02 / 22 / 2016$, and the participants were mainly pharmacy residents. It was the longest period of preparation for clinical practice as it involved strategies to empower pharmacists to go from theory to practice. During this period, participants suggested the inclusion of new strategies in training such as the use of field diaries, rounds of conversations and seminars. These strategies helped pharmacists to understand that they needed more contact with patients and to include a larger number of patients in their panel. Their reflections pointed to the meanings associated with holistic and patient-centered care, the importance of applying a systematic thought process to make decisions about drug therapy and their perceptions about collaborative care. All of these were then included in the new training plan. In Cycle 2, two themes emerged, as discussed below.

\section{Management of change supported by driving forces}

In the other side of the dynamic field of forces, there are the driving forces, which push participants forward, contributing to change and for a stronger conviction about the import of pharmaceutical care. This theme has two sub-themes.
Pharmaceutical care in practice

"Pharmaceutical care is to care for patients. It is to respect their habits and beliefs, and to reach an effective drug therapy while guaranteeing patients' quality of life."

This quote illustrates a participant understanding of pharmaceutical care practice as expressed in a group discussion. They started to perceive how pharmaceutical care is different from everything they did. This professional practice demands responsibility for the outcomes of pharmacotherapy, and this is new for pharmacists. One pharmacist mentioned: "Holism invites us to find the balance between understanding the technical aspects of medications and their meanings for patients." Participants started perceiving that patients have to be seen in their totality and so medications have to be put in the context of patients' lives. The philosophy of pharmaceutical care was gradually apprehended.

Pharmaceutical care is not done alone

Putting pharmaceutical care into practice depends not only on the acceptance of the professional but also of the pharmacist's willingness and ability to communicate and interact with the other members of the health-care team. "A pharmacist cannot do pharmaceutical care alone. To interfere in a patient's pharmacotherapy involves other professionals. Actually, pharmaceutical care is not only a pharmacist's practice."

According to the principles of the Brazilian public health-care system, integral and comprehensive care requires collaboration and use of multiple competencies to care for patients in use of medications. One participant reflects on the importance of collaboration: "The patient is not only ours. It is kind of a clock mechanism, if one piece does not work, the other also stops. All pieces have to function well for the clock to work." Another one says: "But, it takes time. The delivery of CMM will impact the way other professionals see the pharmacist. The expectation of the team is still of that professional that knows a lot about pharmacology, especially mechanisms of actions. This is the culture. It will take time. They will need to experience CMM."

\section{Cycle 3}

The third and last period of pharmacist training began in March 2016 with the expectation of 12 month duration. This cycle lasted from March to December of 2016. Participants spent most of their time in patient consultations under the supervision of tutors. All patients consented to be part of the service as well as of the practitioners training. All consultations followed the patient care process taught during the theoretical part of the training and were documented in electronic charts built specifically for CMM services. Moreover, a summary of each consultation (DTP identified and recommended resolutions) was documented in the patient's paper chart so that other professionals had access to it. Participants were also trained to order laboratory exams to assess medications' effectiveness and safety and to make patients' referrals to other providers. Pharmacists participated in seminars that discussed clinical protocols, physiopathology of diverse health conditions and many other subjects associated with pharmacotherapy and patient-centered care. Laboratory simulations were utilized as a technic to train clinical skills such as clinical decision-making and communication. An actress from the College of Theater participated in the simulations. The following theme emerged during Cycle 3.

\section{Pharmaceutical care fostering professionals' self-efficacy}

Self-efficacy is understood as a person's beliefs about her capacity to organize and execute actions to reach acceptable levels of performance, not being concerned with the person's abilities but with the judgement about what she chooses to do [25]. For the participants in this study, to have clarity about one's professional philosophy as well as to have a propaedeutic that can be utilized with every patient provide them with peace of mind and confidence to assume direct patient care responsibilities, as illustrated in the following narrative: "Nowadays I feel secure to care for patients, to identify DTP... First, I listen to the 
patient. I do stimulate the patient to talk...I understand that I don't need to identify and resolve all DTP at once. I will prioritize the problems according to the needs and wishes of the patient. After identifying DTP, I need to resolve them...that's the reason I need to construct a care plan. So, I make agreements with the patient regarding what we are going to do. Then, I set up a follow-up appointment to assess what happened, the results and keep following this patient."

For participants, pharmaceutical care practice affords them a clear path, or a work process, and a basic thought process that directs their work with a patient. This path boosts their beliefs that they are capable of assessing a patient and making decisions. One participant utters: "I need to ask if every medication is indicated, effective, safe and convenient for that specific patient. I also need to establish a trusting relationship with the patient, respect him, make agreements with him. I didn't learn these things in pharmacy school nor at my specialization course."

Interestingly, at the beginning of this study, most participants saw pharmaceutical care as a theory, but they could not apply it to transform it into a clinical service. In other words, they had the vast pharmacotherapeutic knowledge but did not know how to apply that for the benefit of a patient. "The pharmacotherapy workup is the tool that was missing for me to be able to bring pharmaceutical care to a real patient." This rational thought process, or the pharmacotherapy propaedeutic, can be perceived as one of the most important contributions of pharmaceutical care practice to the profession of pharmacy as it presents a consistent and reproducible decisionmaking the process to assess a patient's pharmacotherapy $[25,26]$. This reasoning process not only permits the logical application of the esoteric knowledge of the pharmacist in an encounter with a patient but also allows and fosters a standardization of a patient care process that focuses on identifying and resolving pharmacotherapeutic problems. This quote of a participant reveals this thought: "Pharmaceutical care and CMM gives us the theoretical and methodological foundation and a work process that guide us on a daily basis. It is a guide that allows us to put our knowledge of pharmacology into practice... I think that without this guide, like a map, it becomes impossible to work consistently with every patient. The philosophy of practice turns us into a real professional and CMM into a service grounded in professional practice."

\section{Cycle 4}

The implementation of CMM services occurred during the cycle. Participants put into practice the knowledge and skills learned during the training, which they called "Management of the practice - a praxis." "Praxis is action and reflection about the world to transform it" [27]. The practice management system is the third component of pharmaceutical care practice and deals with all the resources needed to build a high-quality service [28]. For participants, the management of the CMM service was one of the most challenging aspects of the process of building a new clinical practice. The management system is essential as it involves finding the right human resources, the necessary physical resources, and all the needed support to offer an efficient and reproducible service. It goes from planning to the quality management, communication management and outcomes measurement. In also involves a clear definition of the vision and mission of the service. In this study, the management piece emphasized the partnerships and negotiations needed for the work to happen. The support of management was essential, as proposed by recently published work [29,30]. A partnership with the Center for Pharmaceutical Care Studies (Universidade Federal de Minas Gerais) and Center for data processing of the Universidade de Uberlândia was important for know-how transfer in terms of training, documentation system and data analysis for outcomes measures. As the physical space for patient consultations was guaranteed, the definitions about the documentation process gained a major focus. Documentation has a very important role in any practice, especially in a new practice. The documentation is essential not only for legal reasons but also to produce information about the service, which allows assessment of its impact [11,31,32]. Discussions about the documentation system and its standardization started in June of 2014. It was discussed the importance of documentation for quality management, data safety and production of new knowledge about CMM services. Furthermore, documentation allows for communication between CMM services, CMM and other services in the health-care systems, and CMM and other providers and payers. During this cycle a documentation system was built, the process of documentation in the patient's chart was defined, and patient scheduling was structured. In Cycle 4; 2 themes emerged.

\section{DOCUMENTATION AS THE CONDUCTING WIRE OF THE PRACTICE}

Over time pharmacists recognized the importance of a robust documentation system, as pointed by this participant: “...a wellstructured documentation system is as important as having a process to take care of a patient. It is a requirement of professional practice to document." Moreover, another pharmacist said, "if you don't document you didn't do it."

The documentation was recognized as necessary by participants, even though it was hard for pharmacists.

Patient scheduling was identified as a very important part of the practice management system, as mentioned below. "A major deficiency of our service is scheduling, and we need to change that. We can be more effective in the following up of patients if the scheduling works. The way it is, we are losing contact with patients, and it is frustrating if they don't come back."

After many meetings with the health-care team and administrative personnel, it was understood that scheduling was very important for the sustainability of the service: "The reception desk people have been helpful, and now it will be easy to refer patients to us as well as to have patients back for follow-up appointments."

\section{THE ADVANTAGES OF A SYSTEMATIZED PRACTICE}

Participants realized the importance of following standards of practice to deliver a fine and safe service to patients, and that involves a reliable documentation system: "Structuring a service helps us to follow the patient in a process that makes sense, from the assessment to the intervention and the evaluation of real results."

From the perspective of another participant, the standardization allowed the insertion of the pharmacist in the flow of patients in the clinic: "Now we can see patients in a more effective way. We can interact with the other professionals because we are included in the flow of the clinic, now we see the patients for follow-up and can see the results of what we did."

From the point of view of participants, the systematization of all the work processes allowed the periodic follow-up of patients. The ideal situation would be to have a defined flow between different professionals so that the patient would access integral and comprehensive care: "Even though we advanced our services and now we see patients more than once, we still need to work together with other professionals, communicate better and create a referral and counter-referral system that really works. I think that when this happens patients will benefit tremendously."

This action research project is still under development as pharmaceutical care practice demands a major transformation in all the processes attached to a pharmacist's work. As each cycle developed, the role of the pharmacist became clearer to all around them as well as to pharmacists themselves. The training of pharmacists, the systematization of the work processes and the documentation system is making the work reproducible in the institution where the research took place. All the components of pharmaceutical care practice were discussed and implemented during the time of this project, and the change in the pharmacists' attitudes might have been 
the most important accomplishment of this work, as noted by this participant "We can see the change. We are seeing more patients, and we are more motivated. The involvement of residents has been very important to advance our work in the oncology service. Furthermore, our documentation is better. Moreover, now we can order labs, and we interact better with other providers. When I say that CMM is the gold future of the profession I mean our recognition by the population. In the eyes of the population, we will be seen as a necessary professional."

\section{DISCUSSION}

This study showed how challenging it is for pharmacists to incorporate direct patient care in their work routine. These professionals are pulled in many directions, from administrative and managerial tasks to compounding and to patient care. These are very different activities that usually require different people to execute them and, more importantly, individuals with a different set of competencies. Action research has been a helpful tool to involve participants/pharmacists in a new endeavor such as to engage in the process of major change in a professional's responsibilities and actions [19]. To attempt to involve participants in the process of research as coinvestigators is arduous in a situation where not all of them wish to pursue change. In this study, education and different pedagogical approaches were necessary to create the right conditions for reflection and learning to take place $[16-19,23,24]$. Participants were slowly being introduced to the new work processes required to provide a standardized service and, thus, the initial resistance gave way to a timid feeling of ownership of the work. Throughout the training on the components of pharmaceutical care practice, the attempt to engage and motivate for change, group discussions and the implementation of CMM services, the meanings of participants' experiences were captured and synthesized into six major themes that emerged during four cycles of this action research. Initially, as the first theme denoted, the resistant was striking, and it had to be deeply understood not to become a value judgement on the part of the researchers [33]. The pharmacists' resistance reflected their attachment to what was familiar and comfortable to them, which is the administrative activities traditionally executed in a hospital setting. This is plausible since it is the way these professionals are recognized in the health-care system; they are the professionals responsible for safeguarding medications. For most participants in this study, to leave their administrative responsibilities and adventure into patient care meant to abandon their comfort zone to venture into an unfamiliar world. They are attached to the safety offered by their everyday duties, and it becomes difficult to imagine such a dramatic change. This seems to be the biggest barrier for a change in pharmacists' practices. This is happening when pharmacists are being asked to change the health-care systems, when their impact on patients' outcomes are being questioned and when it is expected they will be substituted by pharmacy technicians in the near future $[34,35]$. Even though resistance in such a context can be seen as natural due to anxiety, insecurity and fear, reflections on this moment pointed to the need to manage this conflict to overcome it. The management of change supported by the driving forces was an important development in this study, as supported by the theory of force filed by Kurt Lewin $[16,17,36]$. This theory teaches us to promote an imbalance by a change in the direction of one of the forces or by adding a new force in a situation. In this study, the driving forces were represented by those participants who wished the change that was mainly the pharmacy residents. The work then followed by engaging these participants to understand their reality, to comprehend the theoretical framework that they would utilize to take care of patients, to systematize their practices so that they would have one common practice and to finally implement sustainable CMM services in the oncology department. That involved learning and utilizing a new vocabulary to communicate between themselves and with other professionals and to organize a credible documentation system $[2,10,11,12]$. Underpinning all of this was learning to be a different kind of pharmacist $[16,19]$. As discussed in the profession of nursing, the systematization of a professional's patient care process is what differentiates a reliable professional from another [37]. This is still a novel subject in the profession of pharmacy. From the perspective of the Brazilian Public Health System, it becomes important to address the meanings of collaborative work. Professionals bring multiple competencies that will necessarily meet when dealing with a patient in use of medication. Participants realized that good patient care involves interdisciplinary work, as pointed by one pharmacist that said: "pharmaceutical care is not done alone." However, working as a team is still a challenge in the health systems. The preparation of health professionals does not follow this logic as different professions have different conceptions of the human being, and it is a mostly Cartesian view that sees humans as a machine that needs repair [38]. This lack of collaboration slows down the process of implementation of CMM services. From the other hand, currently, a patient-centered approach has been considered essential in health care, and it might be what might unite all professionals and what will invite collaboration. This approach favors integration and, consequently, better-shared decision-making and continuity of care, which will lead to better patient outcomes [38-40].

The theme "pharmaceutical care fostering pharmacists' self-efficacy" suggested that the professional was overcoming his or her insecurity. It is believed that the professional with no self-efficacy will not utilize her knowledge or skills to improve patients' outcomes [25]. In order for CMM services to be effectively implemented, we could infer that pharmacists must have a high degree of self-efficacy. Self-efficacy can change the professional path of an individual since stronger beliefs of self-efficacy lead to greater motivation when one is performing tasks $[41,42]$. As one pharmacist mentioned: "When I feel secure, I respect the patient and am more open to make agreements... listening to the patient is the first step for a good decision-making process." This is associated with listening in a patient-centered manner [43]. Regarding the advantages of a systematized practice, participants called our attention to the importance of a logical decision-making the process to the provision of a structured service. Sorensen et al. discussed the importance of a professional not to focus solely on patients' compliance to a medication as they should first assess the appropriateness, effectiveness and safety of a drug product. As shown in the literature $[2,11]$, the rational thought process proposed by pharmaceutical care practice was seen as a very important contribution to the construction of a standardized service and an outcome-driven professional practice. During this study, we experienced the importance of reflection and the interrogation of our own practices [45]. Reflection provided opportunities to go back, reveal what happened and do it differently next time. Reflection in action is a process that fosters professional development, and it has the potential to develop new ways of thinking, of comprehending, of action and of equating problems [46]. This study started to unpack the meanings of systematization of a practice and its importance for quality, reproducibility, and sustainability. As a result, we believe that the model of Kurt Lewin can assist organizations that wish to establish CMM services with satisfactory results. It can also meet the interests of both organizations and academia $[47-49,50]$ as it produced knowledge that promoted change in the studied reality.

\section{CONCLUSION}

This study produced knowledge on the experiences of pharmacists as they lived through the process of initial transformation of their professional practice to offer a patient-centered and systematized service. It was the goal to build a dialogical relationship between researchers and participants that allowed to identify their needs and fears and to respect their previous knowledge and feelings. Even those individuals that chose not to change their practices, all the reflections, discussions and readings brought by the research process, might have minimally shifted their basic way of thinking. This study, as many others, point to the fact that the change required from the traditional pharmacist to the one that accepts pharmaceutical care as his new mission, is exorbitant. Many pharmacists did not choose to be a patient care provider. Moreover, most curricula of pharmacy schools still do not prepare them to assume that responsibility. The organization environment also can work as an impediment to the advancement 
of this practice when professionals still work in an isolated manner without a clear focus on the patient. The framework of Lewin supported the introduction of a new work path for pharmacists, which could be operationalized as an innovative technology for the Brazilian healthcare system: CMM services. The participants of this study could be mobilized to visualize a new way of being a pharmacist. Thus, the investment in the preparation of a new pharmacist, one that is focused on direct patient care, should be seen as a desirable alternative.

\section{ACKNOWLEDGMENTS}

The authors thank the Clinical Hospital of the Federal University of Uberlândia, and the participants of the research for his contribution in the data collection process and implementation of the CMM service.

\section{REFERENCES}

1. BRASIL, Ministério da Saúde. Portaria 874, Publicada em 16 de Maio de 2013. Dispõe Sobre a Política Nacional Para Prevenção e Controle do Câncer na Rede de Atenção à Saúde das Pessoas com Doenças Crônicas no Âmbito do Sistema Único de Saúde; 2013. Available from: http://www. bvsms.saude.gov.br/bvs/saudelegis/gm/2013/prt0874 1605 2013.html. [Last accessed on 2017 Jun 15].

2. Ramalho-de-Oliveira D. Atenção Farmacêutica: Da Filosofia ao Gerenciamento da Terapia Medicamentosa. $1^{\text {st }}$ ed. São Paulo, (SP): RCN; 2011.

3. de Domenico EB. The complexity of oncology care: Current and future challenges. Acta Paul Enferm 2016;29:3-5.

4. Chabner BA, Longo DL. Manual de Oncologia de Harrison. $2^{\text {nd }}$ ed. Porto Alegre: Artmed; 2015

5. Brasil, Ministério da Saúde. Instituto Nacional do Câncer José Alencar Gomes da Silva. INCA. Estimativa 2016: Incidência de Câncer no Brasil, Rio de Janeiro (RJ): INCA; 2015a. Available from: http://www. inca.gov.br/estimativa/2016. [Last accessed on 2016 Dec 16; Last cited on 2016 Feb 18].

6. Bonita R, Magnusson R, Bovet P, Zhao D, Malta DC, Geneau R, et al. Country actions to meet UN commitments on non-communicable diseases: A stepwise approach. Lancet 2013;381:575-84.

7. Balducci L, Goetz-Parten D, Steinman MA. Polypharmacy and the management of the older cancer patient. Ann Oncol 2013;24 Suppl 7:vii36-40.

8. Secoli SR. Polypharmacy: Interaction and adverse reactions in the use of drugs by elderly people. Rev Bras Enferm 2010;63:136-40.

9. Ribeiro MA, Heineck I. Drug storage at home in the community assisted by the family health programme in ibiá, MG, Brazil. Saúde Soc 2010;19:653-63.

10. Strand LM, Cipolle RJ, Morley PC, Frakes MJ. The impact to of pharmaceutical care practice on the practitioner and the patient in the ambulatory practice setting: Twenty-five years of experience. Curr Pharm Des 2004;10:3987-4001.

11. Cipolle RJ, Strand LM, Morley PC. Pharmaceutical Care Practice: The Patient-Centered Approach to Medication Management. $3^{\text {rd }}$ ed. New York, NY: McGraw-Hill; 2012.

12. Isetts BJ, Brummel AR, de Oliveira DR, Moen DW. Managing drugrelated morbidity and mortality in the patient-centered medical home. Med Care 2012;50:997-1001

13. BRASIL, Ministério da Saúde. Portaria No. 4283, de 30 de Dezembro de, 2010. Aprova as Diretrizes e Estratégias Para Organização, Fortalecimento e Aprimoramento das Ações e Serviços de Farmácia no Âmbito dos Hospitais. Brasília: Ministério da Saúde; 2010. Available from: http://www.bvsms.saude.gov.br/bvs/saudelegis/ gm/2010/prt4283 3012 2010.html. [Last accessed on 2017 Jun 10].

14. BRASIL, Conselho Federal de Farmácia. CFF, Resolução No. 585, de 29 de Agosto de, 2013, Regulamenta as Atribuições Clínicas do Farmacêutico e dá Outras Providências, Seção 1, Diário Oficial da União 25 Set; 2013a.

15. Cheng Y, Raisch DW, Borrego ME, Gupchup GV. Economic, clinical, and humanistic outcomes (ECHOs) of pharmaceutical care services for minority patients: A literature review. Res Social Adm Pharm 2013;9:311-29.

16. Mailhiot GB. Dinâmica e Gênese Dos Grupos: Atualidade das Descobertas de Kurt Lewin; Atualidade das Descobertas de Kurt Lewin. Petrópolis, RJ: Vozes; 2013.

17. Kristina H. Field theory and working with group dynamics in debriefing. Simul Gaming 2015;46:209-20.

18. Kristiansen M, Bloch-Poulsen J. Participation in action research:
Between the methodology and worldview, participation and co-determination. Trabalho Educ 2013;22:37-53.

19. Franco MAS. Research -Action Methodology: the Shared Production of Knowledge. UNOPAR Cient., Ciênc. Human 2010;11:5-14.

20. BRASIL, Ministério da Saúde. Departamento de Informática do SUS, DATASUS, Cadernos de Informação de Saúde: Região Sudeste. Brasília, (DF): Ministério da Saúde; 2015b. Available from: http:// www.datasus.gov.br. [Last accessed on 2016 Jun 10; Last cited on 2015 Nov 30].

21. Dahlberg K, Drew N, Nystron M. Reflective Lifwworld Research. Lund, Sweden: Student Litteratur; 2001.

22. Braun V, Clark V. Using thematic analysis in psychology. Qual Res Psycol 2006;3:77-101

23. CEAF/UFMG: Centro de Estudos em Atenção Farmacêutica do Departamento de Farmácia Social da Universidade Federal de Minas Gerais. Available from: http://www.farmacia.ufmg.br/ceaf-2/ apresentacao-7. [Last accessed on 2016 Mar 11].

24. Bion WR. Experiência Com Grupos. São Paulo: EDUSP; 1975.

25. Dahl JR, Hall AM. A scale to measure pharmacy students' self-efficacy in performing medication therapy management services. Am J Pharm Educ 2013;77:191.

26. Amaral MJ, Moreira MA, Ribeiro D. O papel do supervisor no desenvolvimento do professor reflexivo: Estratégias de supervisão. In: Alarcão I, etitor. Formação Reflexiva de Professores: Estratégias de Supervisão. Porto: Porto Editora; 1996. p. 89-122.

27. Freire P. Pedagogia do Oprimido. $54^{\text {th }}$ ed. Rio de Janeiro, RJ: Paz e Terra; 2013

28. Freitas EL, Ramalho de Oliveira D, Perini E. Pharmaceutical Care theory and practice: a possible dialogue? Acta Farmaceutica Bonaerense 2006;25:447-53.

29. Detoni KB, Nascimento MM, Oliveira IV, Alves MR, Gonzáles MM, de Oliveira DR. Comprehensive medication management services in a Brazilian specialty pharmacy: A qualitative assessment. Int J Pharm Pharm Sci 2017:9:227-32.

30. de Oliveira GC, Alves MR, Ramalho de Oliveira D. Action research as a tool for transformation of the pharmacist's praxis in primary care. Int J Pharm Pharm Sci 2017;9:180-5.

31. Cipolle RJ, Strand LM, Morley PC. El Ejercicio de la Atención Farmacéutica. Madrid: McGraw-Hill; 1998

32. Cipolle RJ, Strand LM, Morley PC. Pharmaceutical Care Practice: The Clinician's Guide. $2^{\text {nd }}$ ed. New York: McGraw-Hill; 2004.

33. Garrido G, Saltorato P, Moreira CAA. Psychoanalytic Reflections about Resistance to Organizational Change Reflexiones Psicoanalíticas sobre la Resistencia al Cambio Organizacional. Rev Psicol Organ Trabalho 2015;15:212-23.

34. Rosenthal M, Zubin A, Ross TT. Are pharmacists the ultimate barrier to pharmacy practice change? Can Pharm J 2010;143:37-42.

35. Hall J, Rosenthal M, Family H, Sutton J, Hall K, Tsuyuki RT. Personality traits of hospital pharmacists: Toward a better understanding of factors influencing pharmacy practice change. Can J Hosp Pharm 2013;66:289-95

36. Lewin K. Field Theory in Social Science; Selected Theoretical Papers. New York: Harper and Row; 1976.

37. Amante LN, Rosseto AP, Schneider DG. Systematization of the nursing assistance at the intensive care unit (ICU) based on wanda horta's theory. Rev Esc Enferm USP 2009;43:54-64.

38. Sousa LF, Bastos PRHO. Interdisciplinarity and Training in the Pharmacy Area. Trabalho, Educação e Saúde 2016;14:97-117.

39. AgreliHF,Peduzzi M, Silva MC.Patient centered care in interprofessional collaborative practice. Interface (Botucatu)2016;20:905-16.

40. Makowsky MJ, Schindel TJ, Rosenthal M, Campbell K, Tsuyuki RT, Madill HM. Collaboration between pharmacists, physicians and nurse practitioners: A qualitative investigation of working relationships in the inpatient medical setting. J Interprof Care 2009;23:169-84.

41. Alsharif NZ, Roche VF, Qi Y. Students' perception of self-efficacy following medicinal chemistry skills laboratory exercises. Am J Pharm Educ 2016;80:76.

42. Torisu EM, Ferreira AC. The social cognitive theory and the mathematic teaching-learning process: Considerations on the self-efficacy beliefs in mathematics. Ciên Cognição 2009;14:168-77.

43. Oliveira IV, Freitas EL, Detoni KB, de Oliveira DR. Use of the patient's medication experience in pharmacists' decision making process. Int $\mathrm{J}$ Pharm 2017;7:1-8.

44. Sorensen TD, Pestka D, Sorge LA, Wallace ML, Schommer J. A qualitative evaluation of medication management services in six Minnesota health systems. Am J Health Syst Pharm 2016;73:307-14. 
45. Amaral MJ, Moreira MA, Ribeiro D. O papel do supervisor no desenvolvimento do professor reflexivo: Estratégias de supervisão. In: Alarcão I, etitor. Formação Reflexiva de Professores: Estratégias de Supervisão. Porto: Porto Editora; 1996. p. 89-122.

46. Morris T. E se aristóteles dirigisse a general motors? A Nova Alma Das Organizações, Trad Ana Beatriz Rodrigues; Priscilla Martins Celeste. Rio de Janeiro: Elsevier; 2004.

47. Hepler CD, Strand LM. Opportunities and responsibilities in pharmaceutical care. Am J Hosp Pharm 1990;47:533-43.
48. BRASIL, Cuidado Farmacêutico na Atenção Básica. Serviços Farmacêuticos na Atenção Básica À Saúde, Caderno 1. Brasília: Ministério da Saúde; 2014a.

49. Menelau S, Santos PMF, Castro BGA, Nascimento TG. To carry out researches without action or action research in the area of administration? A methodological reflection. R Adm 2015;50:40-55.

50. Mendonça SA, Meireles BL, de Freitas EL, de Oliveira DR. Pharmacy practices experiential programs in the context of clinical education. Int J Pharm Pharm Sci 2017;9:35-41. 